\title{
MAPEAMENTO E TRAJETÓRIA POLÍTICO-INSTITUCIONAL DO TURISMO NO ESTADO DE GOIÁS ENTRE 1961 E 1990
}

\author{
POLITICAL AND INSTITUTIONAL TRAJECTORY AND MAPPING OF \\ TOURISM IN THE STATE OF GOIÁS BETWEEN 1961 AND 1990
}

\author{
LA CARTOGRAPHIE ET LA TRAJECTOIRE POLITIQUE ET \\ INSTITUTIONNELLE DU TOURISME DANS L'ÉTAT DE GOIÁS, \\ ENTRE 1961 ET 1990 \\ Gisélia Lima Carvalho - Instituto Federal de Educação, Ciência e Tecnologia de Goiás - \\ Goiânia - Goiás - Brasil \\ giselialimacarvalho@gmail.com
}

\begin{abstract}
Resumo
Este artigo se propõe a examinar o processo histórico que engendrou a política de turismo no estado de Goiás. 0 recorte temporal priorizado refere-se ao período que vai de 1961 a 1990, fase pouco diagnosticada na literatura goiana. 0 estudo pautou-se no inventário da legislação goiana voltada para o turismo, na análise dos planos dos governos do referido período e no mapeamento das ações mais relevantes de cada governador que contribuíram para desenvolver a atividade no Estado. 0 s resultados evidenciaram que houve uma importante participação do Estado na condução da atividade desde a década de 1960, quando passaram a ser identificadas medidas capitais para a institucionalização do setor, assim como foram averiguadas ações materializadas em um conjunto comum de municípios capazes de transformá-los nos principais destinos turísticos goianos que hoje conhecemos. Palavras-chave: política de turismo, institucionalização, estado de Goiás.
\end{abstract}

\begin{abstract}
This article aims to analyze the historical process that gave rise to the tourism policy in the state of Goiás. The research main time frame is from 1961 to 1990, which is a period not sufficiently studied in Goiás literature. The research is based on an inventory of Goiás tourism legislation, analysis of government plans for the period studied, and mapping of most relevant actions of each governor that contributed to tourism development in the state. The results showed that the state government played a key role in the promotion of tourism since the 1960s, when crucial measures began to be taken in order to institutionalize the sector, and when concrete actions were orchestrated by a group of cities, which resulted in making them the main tourist destinations in Goiás. Keywords: tourism policy, institutionalization, state of Goiás.
\end{abstract}

\section{Resumé}

Cet article vise à examiner le processus historique qui a engendré la politique du tourisme dans l'État de Goiás. Le coupure temporel priorisé se réfère à la période de 1961-1990, la phase sous-diagnostiquée dans la littérature de Goiás. L'étude a été guidé dans l'inventaire de la législation de Goiás orientée vers le tourisme, dans l'analyse des plans des gouvernements de cette période et dans la cartographie des actions les plus pertinentes de chaque gouverneur, qui a aidé à développer l'activité en l'état. Les résultats ont montré qu'il y avait une importante participation de l'État dans la conduite des affaires depuis les années 1960, quand ils ont commencé à identifier des mesures capitales à l'institutionnalisation du secteur, ainsi que ont été constates dês actions matérialisées dans un ensemble commun de municipalités capables de les transformer dans les principales destinations touristiques de Goiás que nous connaissons aujourd'hui. Mots-clés: la politique du tourisme, l'institutionnalisation, l'État de Goiás. 


\section{Considerações iniciais}

Se comparada à política de turismo no Brasil, a trajetória do turismo em Goiás não é tão recente quanto parece, nem as medidas para estimulá-lo. No entanto, delinear essa trajetória, como já identificaram Almeida (2002) e Teixeira (2013), é uma tarefa desafiadora em função da falta de uma memória institucional alimentada por arquivos, documentos e relatórios de atividades organizacionais do governo estadual.

A narrativa que se segue, do ponto de vista metodológico, utilizou de pesquisa documental, composta pelo levantamento da legislação goiana voltada para o turismo, de modo a averiguar se havia menções claras à atividade turística na macrogestão de cada governo, assim como na escala municipal. ${ }^{1}$ Aponta-se uma necessidade paralela de verificar como os governos estaduais se aparelharam para viabilizar as políticas derivadas da esfera nacional, bem como para delinear intervenções complementares àquelas que permitiram construir uma agenda de ações para o turismo goiano. Com essa estratégia, apresenta-se uma periodização composta por dois momentos: o primeiro caracteriza-se pela construção do aparato institucional do turismo (entre 1961 e 1978) e o segundo abrange um período em que ocorre a emergência de novos discursos e temas (entre 1979 e 1990).

Na empreitada de traçar o panorama da política de turismo em Goiás e de verificar como os diferentes governos estaduais assimilaram a política nacional de modo a planejar e a encaminhar suas próprias intervenções, o artigo assegura que houve uma importante participação do Estado na condução da atividade desde 1961, quando foram identificadas as primeiras medidas setoriais para um conjunto comum de municípios, que os consolidou como destinos atuais, tencionando fomentar seu desenvolvimento e ampliando seu potencial gerador de emprego e renda.

Construção do aparato institucional do turismo (1961-1978)

Os primeiros instrumentos legais que permitiram a regulamentação da atividade turística no Estado foram identificados no início da década de 1960, quando, na gestão de Mauro Borges Teixeira (1961-1964), houve uma intervenção estatal ordenada por meio de um plano com objetivos e metas. 
No documento intitulado Plano de Desenvolvimento Econômico de Goiás (1961-1965), ${ }^{2}$ detectam-se as primeiras intervenções governamentais planejadas para exortar a atividade turística. As estratégias adotadas, como mostra o Figura 1, eram destinadas somente a três municípios: a) Goiânia (150.306 hab.), por ter o atributo de uma capital moderna, que representava o vertiginoso desenvolvimento do Oeste brasileiro e que formaria com Brasília um circuito turístico de negócios; b) Caldas Novas (28.478 hab.), que deveria ser transformada em estância hidromineral, aparelhada para fins sanitários e turísticos; c) Cidade de Goiás (6.315 hab.), monumento histórico e artístico do Brasil Central que deveria passar por um processo de restauração e preservação. Nota-se, pela análise do plano, batizado de "Plano MB" (Mauro Borges), um forte vínculo com o nacional-desenvolvimentismo, estilo de gestão e planejamento centralizados na mão do poder público e amparados por um corpo inédito de tecnocratas que poderia ter alterado profundamente a estrutura administrativa vigente do estado de Goiás, caso sua atuação não tivesse sido abortada pelo golpe militar.

O Plano de ação do governo Otávio Lage de Siqueira: triênio 19681970 (Goiás, 1968a), ${ }^{3}$ cuja orientação teria sido dada pelo governo central por meio das diretrizes para uma política nacional de turismo, ${ }^{4}$ também galgou um Estado desenvolvimentista, a partir do amplo apoio à indústria e à agropecuária. Tendo em vista que, em 1970, o estado registrava 2.997.570 habitantes (IBGE, 1971), justificada estava a preocupação quanto ao estabelecimento de uma sólida infraestrutura viária, com a pavimentação de cerca de $2.800 \mathrm{~km}$ de rodovias estaduais e federais, com rede de transmissão e distribuição de energia elétrica, ampliação dos sistemas de produção etc. (Goiás, 1968a), como revela a Figura 2.

Setores como o turismo, a cultura e o meio ambiente foram pouco notados. Em relação ao planejamento do turismo. Há referências quanto à criação de um departamento que iniciaria a implantação da PNT dentro do programa do Conselho Nacional e deveria coordenar o assunto e criar um conselho estadual que, por sua vez, seria o órgão incentivador e normativo das atividades turísticas no Estado. 
Gisélia Lima Carvalho

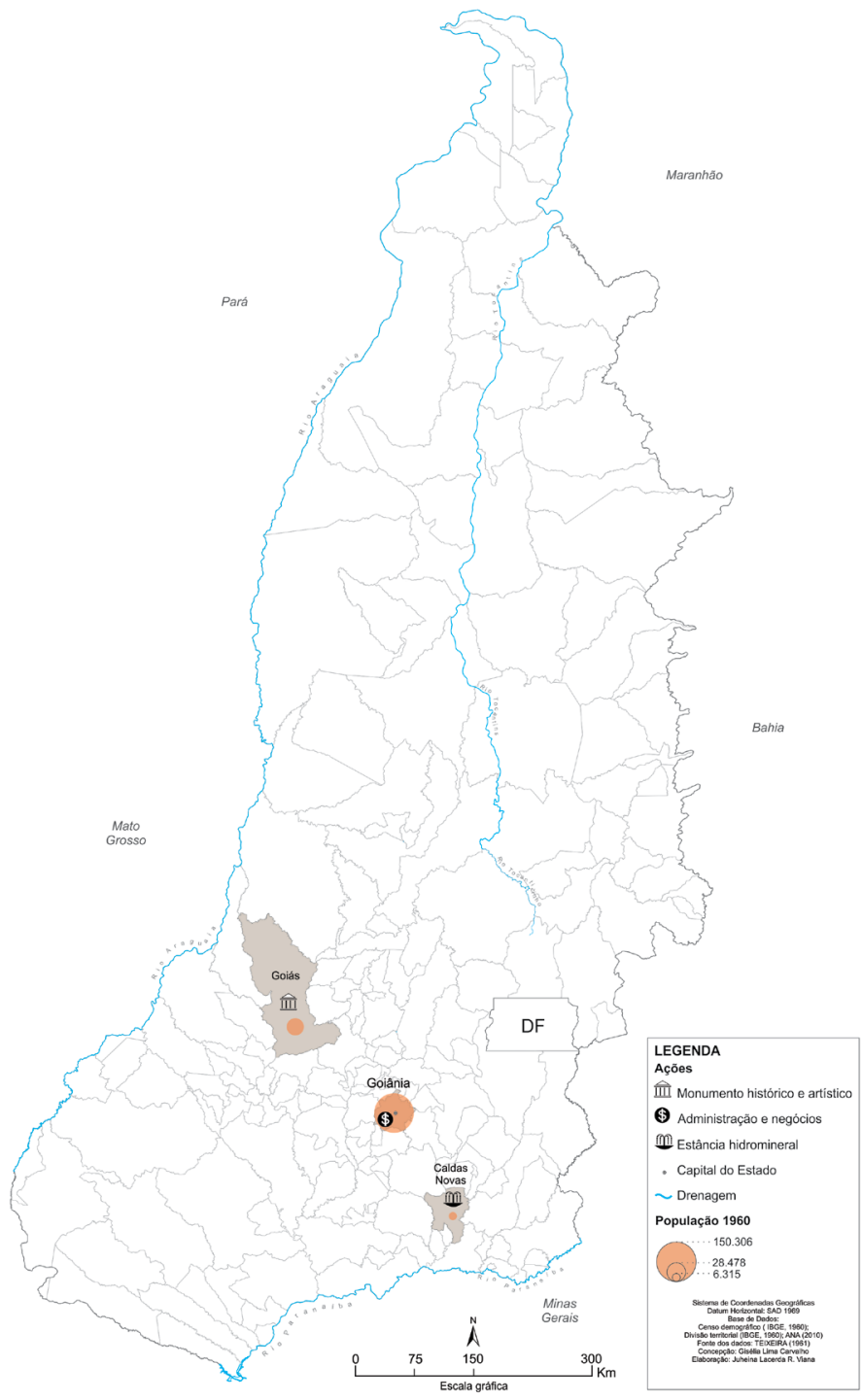

Figura 1 - Mapa da política de turismo no estado de Goiás: ocorrência de ações no governo de Mauro Borges (1961-1965) 


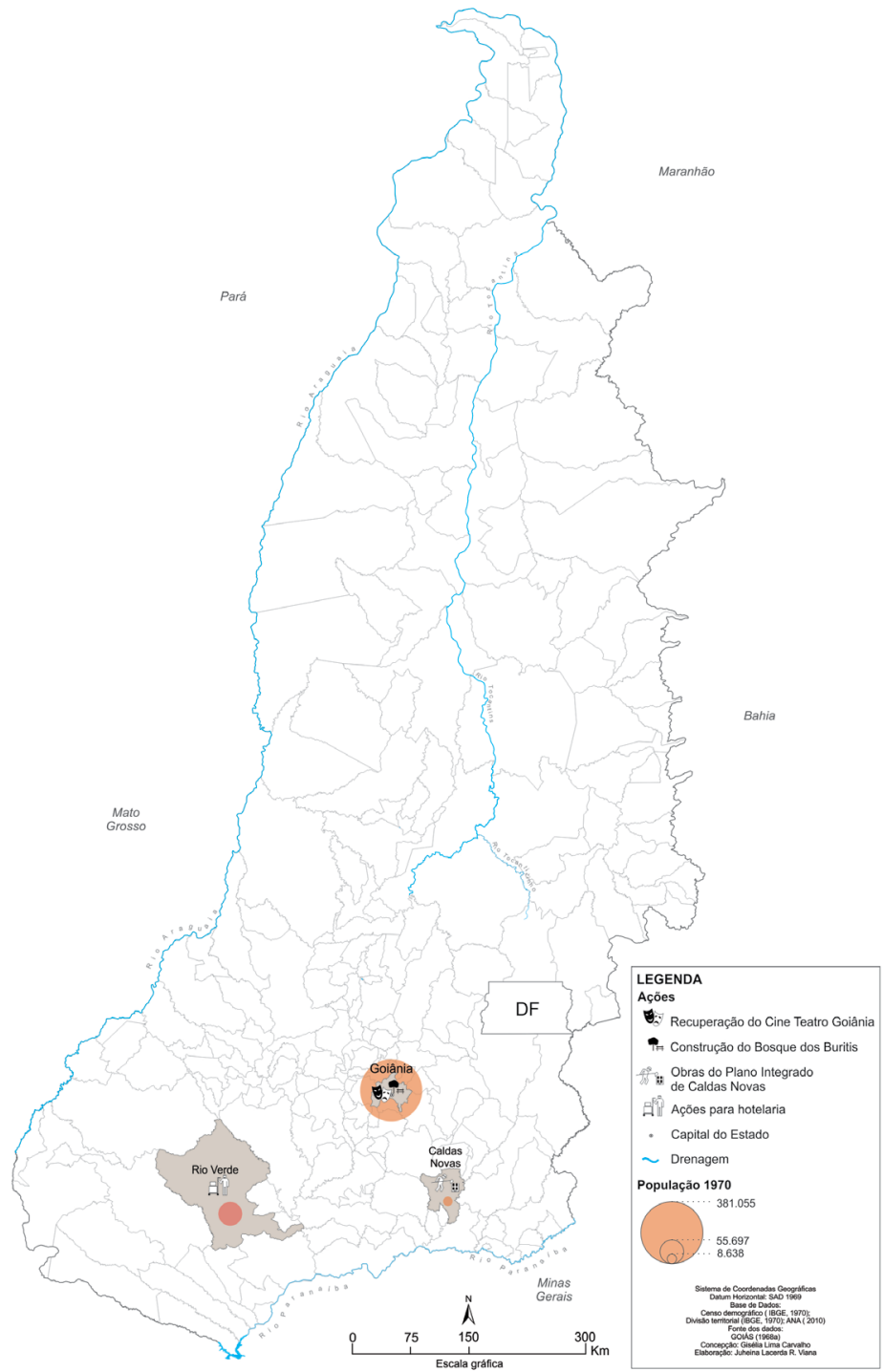

Figura 2 - Mapa da política de turismo no estado de Goiás: ocorrência de ações no governo de Otávio Lage de Siqueira (1968-1970) 
Vê-se aqui um reflexo da política nacional já estabelecida em 1966, pelo Decreto ${ }^{0} 55$, embora as ações ainda sejam restritas a poucos municípios, como Goiânia, Caldas Novas e Rio Verde, e não se debrucem sobre a construção de novos destinos. Em termos de maior relevância, cita-se a construção do Bosque dos Buritis em Goiânia, a recuperação do Cine Teatro Goiânia (a capital contava com 381.055 habitantes em 1970), a execução das obras do Plano Integrado de Caldas Novas, além da publicação de um guia turístico de Goiás. Apesar da pouca atenção dada à estruturação da atividade no Estado, o próprio governador participou do $1^{0}$ Encontro Brasileiro de Turismo, sediado no Rio de Janeiro, com a intenção de inserir o estado de Goiás no roteiro nacional de turismo (Goiás, 1968b).

As ações mais ousadas e estruturantes para o setor turístico goiano foram identificadas nas Linhas de ação de Leonino Di Ramos Caiado (1972-1974) (Goiás, 1971),algo pouco assinalado pela literatura goiana. No diagnóstico elaborado pela equipe de Caiado, reconhecia-se um aproveitamento incipiente do potencial do Estado, ou, como foi denominado, uma "relativa estanqueidade", tendo em vista as oportunidades para a obtenção de resultados econômicos mais expressivos. Cumprindo a função organizativa, o Departamento de Turismo (DETUR) ${ }^{5}$ foi então formalizado, tornando-se uma estrutura jurídico-administrativa e de maior autonomia e enquadrando-se como iniciativa governamental vinculada à PNT, capaz de construir um suporte organizacional necessário ao desenvolvimento do turismo no Estado. A esse órgão caberia "exercer uma ação normativa, coordenadora, fiscalizadora e de gestão direta, em caso de insuficiência da iniciativa privada” (Goiás, 1971, p. 124).

Por meio do planejamento como ferramenta, foi traçado um conjunto de programas com diagnóstico, estudos de viabilidade de oferta de produtos, promoção de convênios etc. para destinos já conhecidos do Estado e outros novos, passíveis de estímulos. Como consequência, vários projetos privados se fizeram presentes na gestão de Caiado, tais como: instalação de empresas de turismo em Goiânia; ampliação do parque hoteleiro de Caldas Novas via projetos urbanos, do Parque das Águas e da Pousada do Rio Quente; implantação e ampliação do turismo no rio Araguaia; experimentação de empreendimentos turísticos em Itajá, Itiquira e Pirenópolis; estudos de viabilidade de implantação de rede de motelaria ao longo da Belém-Brasília. Há menções claras quanto à criação da primeira fonte artificial de água termal de Caldas Novas (poço), em 1973, e a estratégias 
de marketing em um documento promocional chamado de "O Rio Praia". O DETUR elaboraria o ousado Plano de Aproveitamento Integrado do Vale do Araguaia, que permitiria a prática de safári no Parque Nacional do Araguaia. Assim feito, apresentaria informações concretas aos investidores sobre a escolha das áreas para investimento sob sua coordenação. Este era um exemplo da carta de potenciais concentrados no Estado, à disposição de possíveis empresários país afora.

Conforme apontou relatório do sucessor de Caiado, o maior impacto da ação empresarial, tanto em quantidade como em qualidade de hotéis, foi sentido em Caldas Novas (Goiás, 1976). Acrescentam-se, ainda, importantes ações de proteção do patrimônio das cidades históricas de Goiás e Pirenópolis, para a divulgação do valor turístico e cultural e de estímulo à hotelaria (Figura 3).

Almeida (2002) afirma que nesse governo foram adotadas medidas importantes para o turismo por meio do DETUR e do Grupo de Trabalho de Turismo (GTT). ${ }^{6}$ Este último deveria identificar as principais regiões goianas com potencialidades turísticas para uma posterior implantação do Sistema Estadual de Turismo. Diante desses feitos, há que se atribuir a devida responsabilidade a Leonino Caiado pelo desenvolvimento do setor em Goiás a partir da construção de uma agenda formal e institucional que assimilou a importância de parte dos instrumentos que compõem a política de turismo (Velasco González, 2007). Nas palavras do governador Leonino Caiado, há clara intenção quanto à criação de uma política para o turismo:

Dirigirei o esforço de meu governo no sentido da criação de uma política de turismo com um trabalho em profundidade para o aproveitamento racional e efetivo do manancial de cultura, arte e beleza de nossas tradições: ao incremento de nossas estâncias balneárias e a recuperação do Vale do Araguaia. (Goiás, 1971).

Na análise dos documentos referentes à gestão desse governador, há referências evidentes à parceria público-privada. Um exemplo disso é o que se visualiza nos documentos promocionais propostos pela Secretaria da Indústria e Comércio, intitulados Venha ganhar dinheiro em Goiás e “Goiás - um convite ao investimento", cuja meta para o turismo era torná-lo bastante produtivo de modo a contribuir para a renda interna do estado. Os documentos divulgavam imagens de vários pontos turísticos do Estado, como cidades históricas, recursos aquáticos, grutas e formações rochosas, além das fortes evidências de demanda para alguns destinos (Figura 4). 


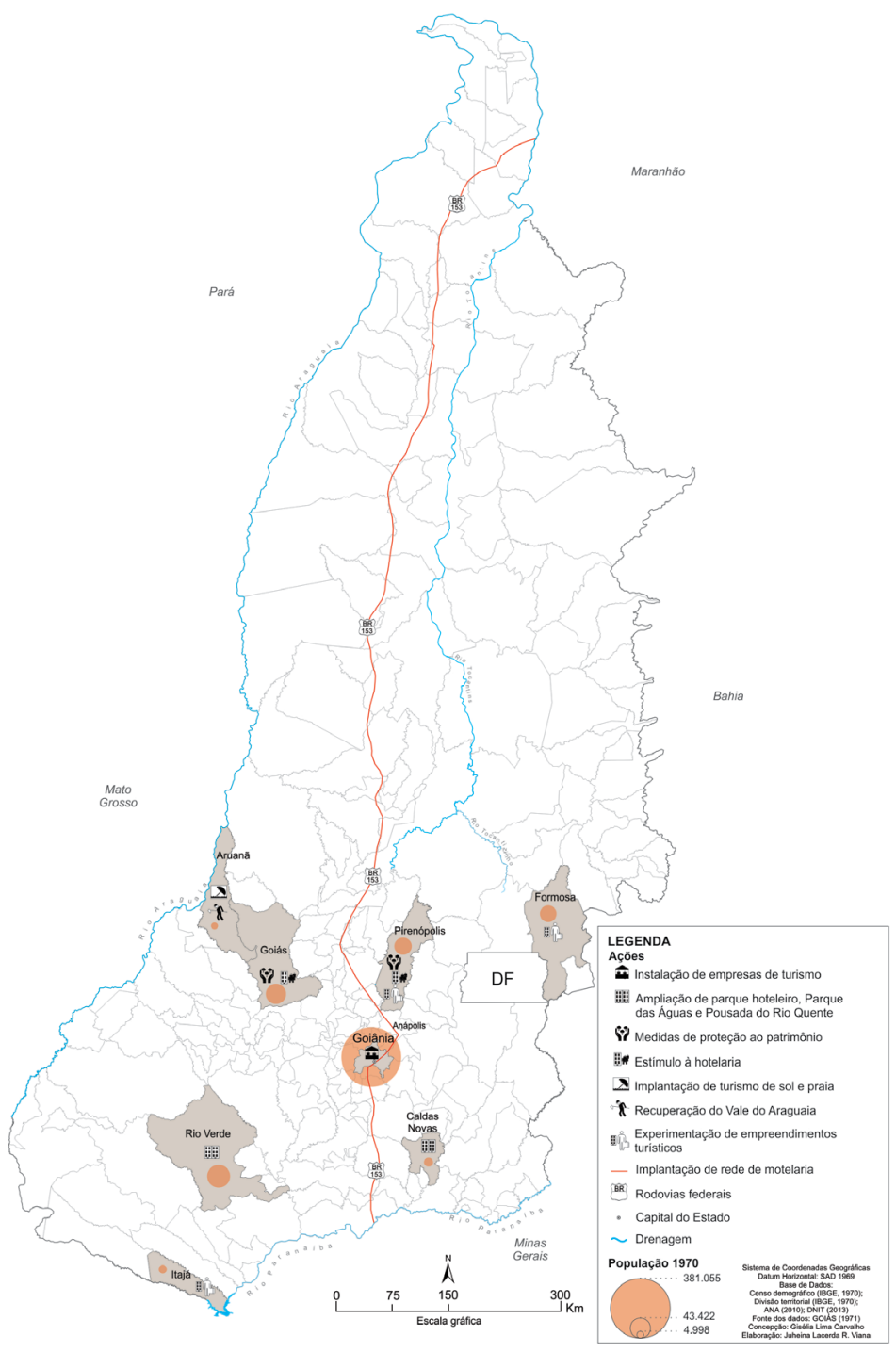

Figura 3 - Mapa da política de turismo no estado de Goiás: ocorrência de ações no governo de Leonino Di Ramos Caiado (1972-1974) 

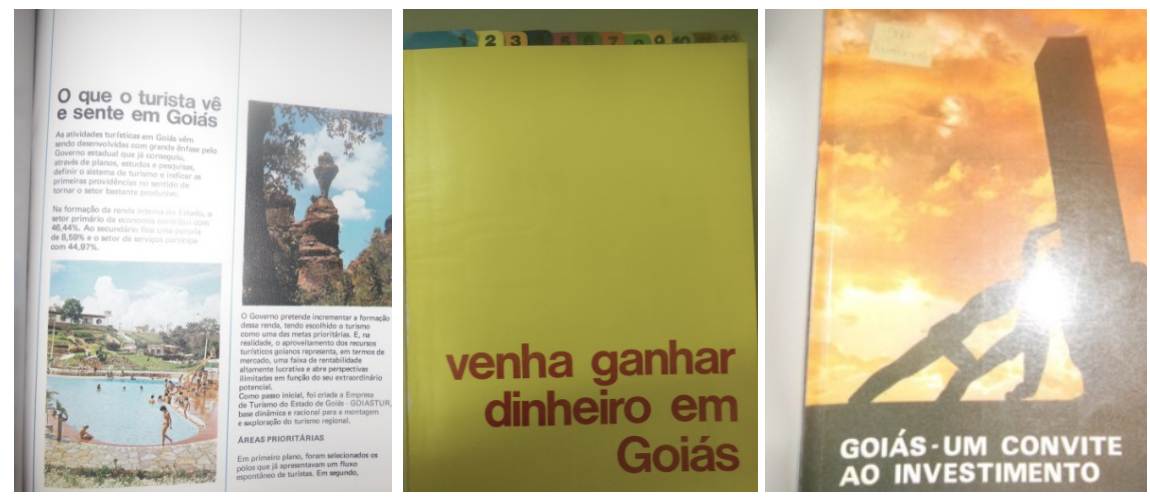

Figura 4 - Documentos de divulgação do estado de Goiás para investidores internos e externos, 1972 Fonte: Goiás (1971).

Ainda na administração de Caiado, em 1972, foi definida, à luz do contexto nacional, a Política Estadual de Turismo, que criou o Conselho Estadual de Turismo (CONTUR) e a Empresa de Turismo do Estado de Goiás (GOIASTUR), vinculada à Secretaria da Indústria e Comércio, com natureza de empresa pública e a finalidade de executar a Política Estadual de Turismo. ${ }^{7}$ Solha (2004), amparada em Beni (1991), afirma que a denominação "Empresa de Turismo" era predominante nos Estados e, com o passar dos anos, foi substituída ou mesmo extinta.

A Política Estadual de Turismo de então compreendia o conjunto "de diretrizes e normas de orientação e estímulo às iniciativas e atividades, do setor público ou privado, dirigidas para o campo do turismo, reconhecidas e declaradas de interesse para o desenvolvimento econômico, social ou cultural do Estado de Goiás" (Art. $1^{\circ}$ ), e deveria ser formulada e executada pelo Sistema Estadual de Turismo (Goiás, 1972). Ressalve-se que, na esfera federal, o governo destinou, nesse período, recursos para a formulação da PNT, o que gerou uma série de repercussões nos Estados, como ocorreu em Goiás. O contexto da época pode ser elucidado por Solha (2004), que afirma que a década de 1970 foi representativa para a política no âmbito dos Estados, uma vez que, orientados por uma política nacional, criaram seus primeiros organismos de turismo sob a forma de diferentes estruturas (secretarias, departamentos, divisões, conselhos, fundos etc.) que pudessem alavancar o setor. 
No governo de Irapuan Costa Júnior (1975-1979) também foi assegurada uma intenção política para o turismo estadual, que seria orientada de maneira a tornar-se compatível com a PNT. Como principal ferramenta para o estímulo ao setor, criou-se o Fundo de Desenvolvimento do Turismo (FUNDETUR), instituição financeira com a seguinte característica:

[...] estrutura contábil e natureza financeira própria, destinado a fomentar e prover recursos para o funcionamento de obras, serviços e atividades turísticas do Estado, bem como a garantir a liquidez de empréstimos de qualquer natureza e o cumprimento de obrigações decorrentes de convênios e contratos firmados com entidades públicas ou particulares. (GOIÁS, 1975).

As estratégias adotadas estavam vinculadas, nessa administração, às Diretrizes gerais e setoriais da ação do governo Irapuan Costa Júnior (Goiás, 1976). Do ponto de vista do contexto econômico, a agricultura passava por intenso processo de modernização para atender às demandas nacionais por exportação.

Os esforços do governo federal, com a criação de programas como o Programa para o Desenvolvimento do Cerrado (POLOCENTRO) e a Geoeconômica de Brasília, privilegiaram o Centro-Oeste e em especial Goiás, segundo Arrais (2007). Do ponto de vista da política do lazer e do turismo, o plano do governo Irapuan Costa Júnior evidenciava a falta de uma política clara para o setor, a despeito das ações anteriores (Figura 5).

Existiam os equipamentos, mas eram de baixa utilização e se limitavam à construção de quadras de esportes e estádios. Reconhecia-se o potencial da atividade como estimuladora da economia desde a criação do DETUR, cinco anos antes, mas as atrações que mereciam mais interesse limitavam-se às cidades de Brasília e Goiânia. Na linha do planejamento, a GOIASTUR já levantara estudos sobre o fluxo de turistas, a capacidade de recepção e projeção de impactos econômicos (Goiás, 1976). Das conclusões do diagnóstico, apontaram-se as seguintes:

a) Goiânia apresentava um parque hoteleiro, em 1974, com 1.168 leitos e 704 aposentos com taxa de ocupação anual em torno de $80 \%$ e dispêndio médio pelos turistas de Cr\$ 2.233,00 (dia/per capita);

b) A cidade de Aruanã, portal do turismo no Rio Araguaia, registrou, em julho de 1973, a chegada de 1.691 turistas proporcionando um ingresso de 532 mil cruzeiros no município; 
c) Em Pirenópolis, na Festa do Divino, em 1973, entraram 2.606 turistas impactando o município com 147 mil cruzeiros (GOIÁS, 1976, p. 96-97).

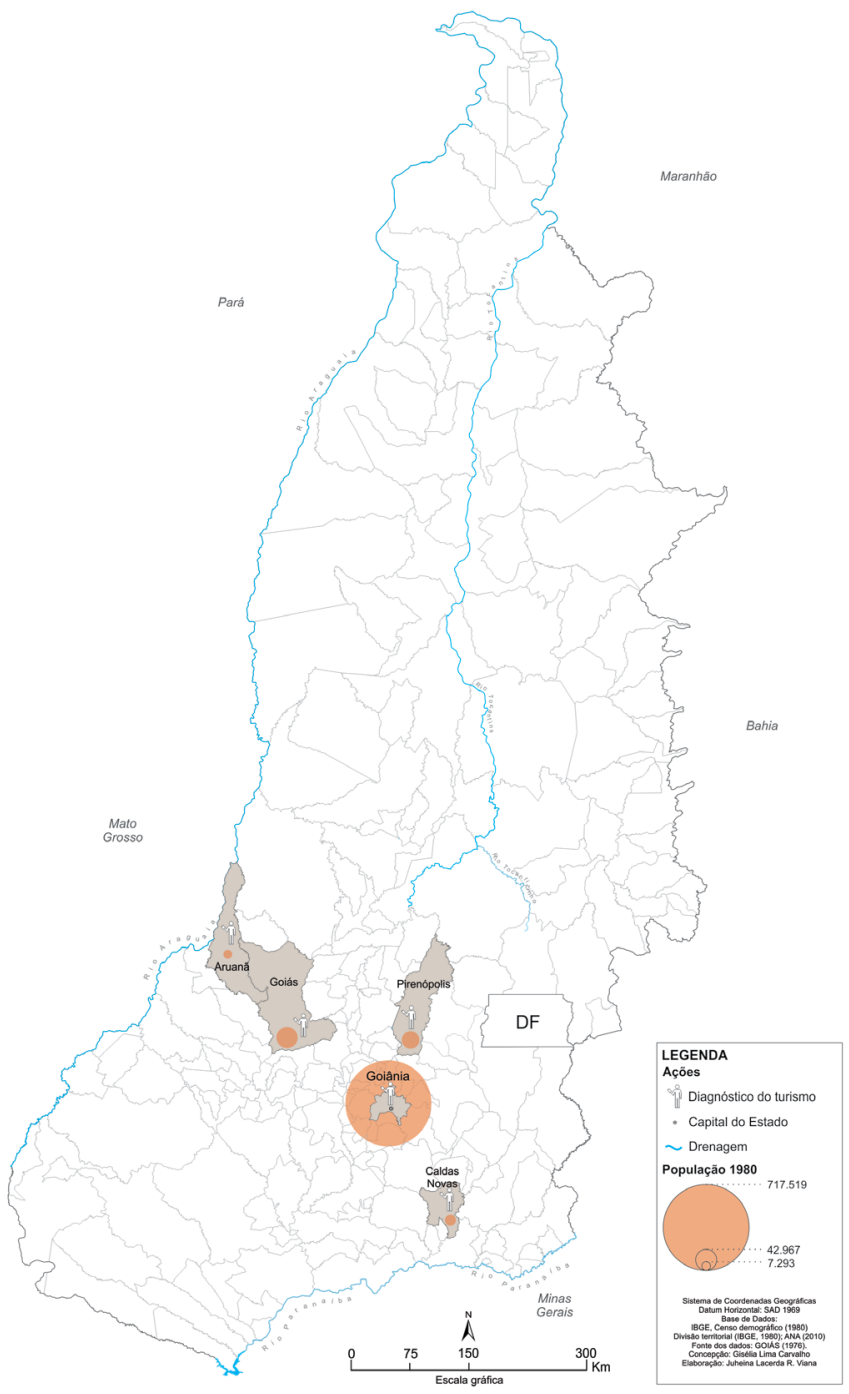

Figura 5 - Mapa da política de turismo no estado de Goiás: ocorrência de ações no governo de Irapuan Costa Júnior (1975-1979) 
De certo modo, o plano de governo reconhecia um nível de planejamento por parte do então órgão público do turismo: "Se, por um lado faltaram condições materiais ao Sistema Estadual de Turismo para atuar mais agressivamente, de outro, serviu muito bem para ativar a iniciativa privada em busca de projetos potenciais” (Goiás, 1976, p. 97). Assim, vários apontamentos foram feitos no sentido de dirimir entraves já existentes nos municípios dotados de uma estrutura turística - como Goiânia, Caldas Novas, Cidade de Goiás e Aruanã -, tais como a falta de preparação da mão de obra, a inexistência de uma linha de crédito no Estado, a situação da infraestrutura de apoio, transporte, energia e saneamento, bem como a ainda reduzida diversificação das opções de lazer para o turista.

Segundo o Anuário Estatístico de Goiás de 1978 (Goiás, 1979), havia no Estado, em 1977, 128 registros de meios de hospedagem, com entrada de 382.472 hóspedes e 1.868 empregados. Chama a atenção o caso de Caldas Novas, cujos 24 empreendimentos receberam naquele ano um total de 115.222 hóspedes e já contavam com o corpo de 635 empregados somente no setor hoteleiro. No presente contexto analisado, as diretrizes de Costa Júnior (GOIÁS, 1976) admitiam que a viabilidade do turismo no Estado dependeria de uma política para ativar os polos já reconhecidos, mediante a elaboração de um programa de complementação turística interna e uma integração com a política de turismo do Distrito Federal. É importante destacar que o referido plano corroborava as medidas anteriores, mas realçava a preocupação com a conservação do patrimônio histórico e a constituição de museus, com a expansão das artes e das feiras artesanais, seguindo uma linha de abordagem já apontada na ótica nacional.

Nessa primeira fase da política de turismo goiano, além da construção do aparato institucional da atividade, já se nota um direcionamento para alguns municípios de evidente potencial e um planejamento estatal voltado para estimular o empresariado com metas relativamente claras, sob a orientação das diretrizes nacionais criadas, embora não se registrem estímulos financeiros advindos do governo federal. O que não era de se estranhar, uma vez que, no contexto nacional, o esforço de desenvolvimento deveria privilegiar, para o Centro-Oeste, máxima mobilização possível para o vasto potencial agropecuário e agroindustrial, inclusive nas áreas de Cerrado, consoante o III Plano Nacional de Desenvolvimento, ou PND (Brasil, 1981). 
Na trajetória de quase vinte anos de institucionalidade do turismo em Goiás, depreende-se uma atividade de pouco peso na economia goiana, sobretudo se colocada diante dos vertiginosos impactos agropecuários já consagrados nas terras locais. Entretanto, uma nova atividade econômica estava sendo alicerçada sob os créditos lançados pelo poder público, sob a proposição dos primeiros instrumentos legais necessários para edificar a Política Estadual de Turismo e sob a noção da importância de planejar. É muito importante ressaltar que esse conjunto de medidas e preocupações em formatar e orientar a atividade permitiu esboçar o mapa do turismo goiano. Municípios como Caldas Novas, Pirenópolis e aqueles banhados pelo rio Araguaia foram repetidas vezes alvo de ações nesse interregno.

\section{A emergência de novos discursos e a discrição do poder público (1979-1990)}

Os elementos mais próximos do campo do turismo vislumbrados no plano do governo de Ary Valadão (1980-1983) foram tímidas ações voltadas para a cultura e o meio ambiente. $\mathrm{O}$ ápice do seu programa foram intervenções na educação e na cultura, como a construção de edifícios públicos para abrigar casas de cultura e difundir os chamados "bolsões culturais” espalhados pelo Estado, especialmente em Goiás, Jaraguá, Pilar de Goiás e Pirenópolis.

No que tange ao meio ambiente, mesmo diante das falhas de proteção dos recursos naturais no Estado e diante dos efeitos do amplo investimento na indústria, algumas medidas sutis tomadas para o funcionamento das Unidades de Conservação criadas se destacaram desde o início de 1960. No entanto, no relatório de gestão do então governador (Valadão, 1983), a GOIASTUR descreveu um rosário de casos de hotéis construídos, sem evidência de incentivo público, em várias cidades do Estado (Catalão, Caldas Novas, Itumbiara, Goiânia, Porto Nacional e Araguacema), como as mais importantes intervenções dessa gestão. Além dessas ações conduzidas pela iniciativa privada, foi identificada uma medida de caráter residual: o uso de campanhas de publicidade destinadas a grupos de excursionistas. Almeida (2002) confirma que havia, de fato, nesse governo, uma tentativa de dinamização do turismo a partir do estímulo à iniciativa privada, e que sua marca passou a ser a divulgação nacional e internacional daqueles destinos nos quais a atividade estava mais estruturada (Goiás, Caldas Novas, Vale do Araguaia) e daqueles que 
apresentavam algum potencial ecológico reconhecido (Corumbá de Goiás e Formosa). Isso só vem reafirmar o papel desempenhado pelos gestores do período anterior no sentido de terem, ao seu modo, estruturado um roteiro de destinos viáveis para divulgação (Figura 6).

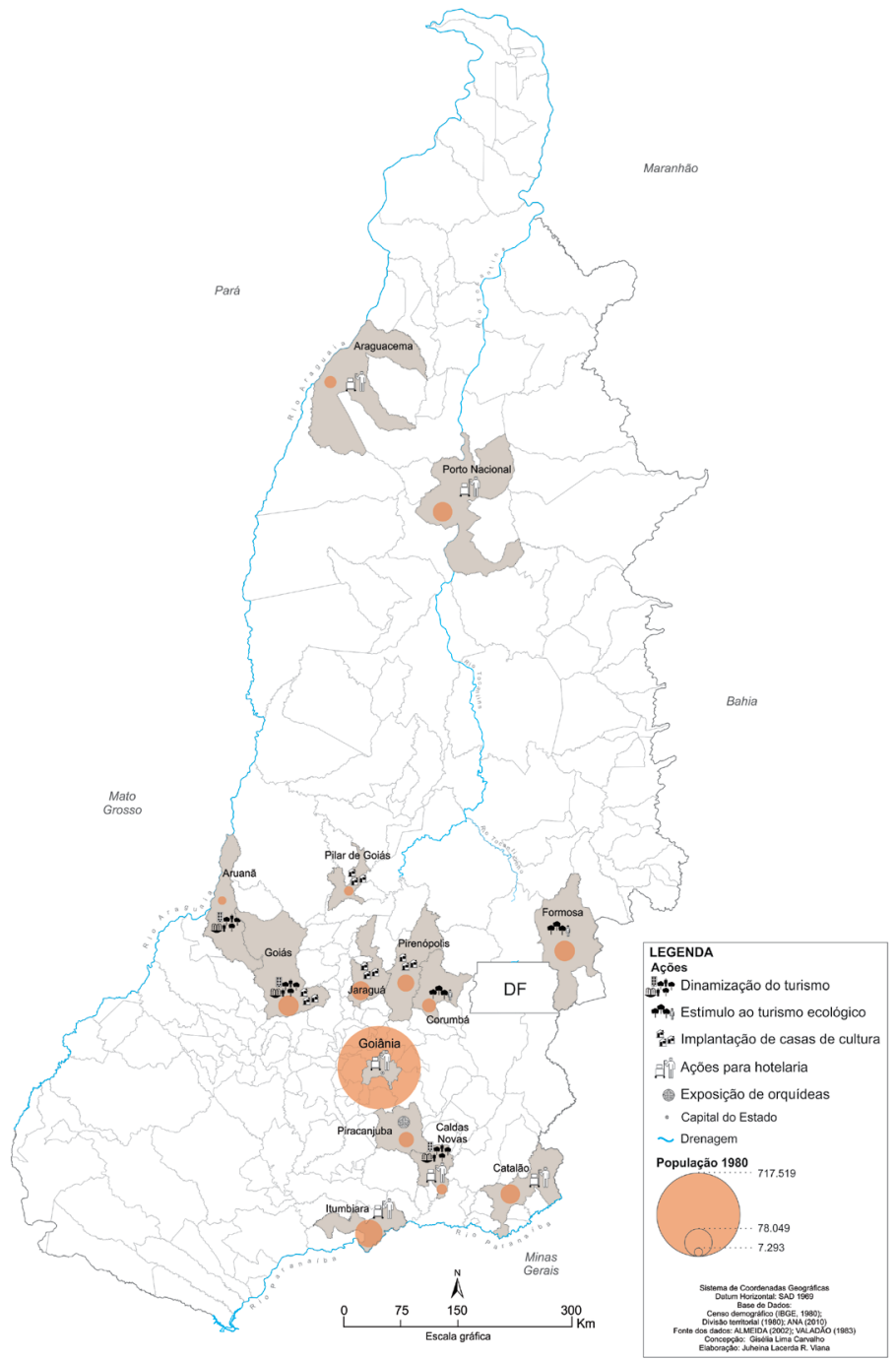

Figura 6 - Mapa da política de turismo no estado de Goiás: ocorrência de ações no governo de Ary Valadão (1980-1983) 
Fica claro que Ary Valadão aproveitou para atrair divisas para o Estado que incrementassem e diversificassem sua economia, a partir do produto preparado pelos governos anteriores e preferiu dedicar-se decisivamente ao setor agropecuário e ao programa de industrialização goiana. Essa medida foi conduzida pelo governo federal, cujas orientações eram restritas à modernização do parque hoteleiro brasileiro e à divulgação de atrativos, segundo Solha (2004).

A gestão política de Iris Rezende (1983-1986) para a atividade em Goiás parece contraditória. Se, por um lado, logo no início da sua gestão ele autorizou mudanças no sistema administrativo do Poder Executivo e extinguiu a GOIASTUR, ${ }^{8}$ criando um órgão menor, a Superintendência do Turismo de Goiás, ${ }^{9}$ por outro, propôs uma alteração na conjuntura do turismo ao lançar o Plano global de trabalho do governo de Iris Rezende (1983-1987) (GOIÁS, 1984a), que se desdobrava em doze planos setoriais. O turismo situava-se no plano: Indústria, Comércio e Turismo, segundo o qual objetivava atingir "manutenção e crescimento do nível de emprego; redução das desigualdades regionais; e descentralização administrativa, desburocratização e aperfeiçoamento institucional” (Goiás, 1984b, p. 9).

No referido documento, há referências de destaque ao interesse do governador em constituir um setor mais organizado, profissionalizado, com prioridades voltadas para o fortalecimento de empresas de turismo; a promoção de melhorias na mão de obra para o turismo receptivo, no sistema de comercialização dos produtos, nos incentivos fiscais para a ampliação do parque hoteleiro, nos atrativos folclóricos, artesanais, históricos e culturais, segundo as regiões; o direcionamento de recursos para equipamentos destinados às classes de baixa renda; a criação de programas de turismo e lazer para o funcionalismo estadual, sobretudo nas férias escolares. Um dado relevante nesse plano foi a presença inédita de programas específicos para todos os setores, bem como de projetos ou atividades correlatas.

No setor aqui referido, foram identificados quatro programas de ação: a) programa de informações comerciais, turísticas e de serviços; b) programa de promoção comercial; c) programa de extensão comercial e d) programa de promoção e extensão turística, folclórica e artesanal (Goiás, 1984b). 
Havia uma preocupação genérica com o turismo estadual que retomava a reestruturação devida e articulada com os interesses das diretrizes nacionais, mas não especificava espaços de atuação, sugerindo uma falta de clareza dos programas ou mesmo de conhecimento dos potenciais turísticos do Estado. Apenas os já tradicionais municípios turísticos são citados dentro de um programa de melhorias da infraestrutura turística, tais como Caldas Novas, Goiás, Goiânia, Pirenópolis e Corumbá.

Almeida (2002, p. 201) assegura que essa administração foi beneficiada pela "assinatura de Protocolo de Intenção entre a GOIASTUR ${ }^{10}$ e a Embratur, como objetivo de desenvolver ações promocionais para fomentar o turismo no Estado". Para a execução desse acordo entra em jogo a parceria do estado com o Serviço Nacional de Aprendizagem Comercial (SENAC) ${ }^{11}$ para qualificar e treinar a mão de obra para o setor.

Ao final da década de 1980, identificou-se a campanha de marketing "Goiás é Bom Demais", ${ }^{12}$ da Superintendência Estadual de Turismo, para divulgar os pontos turísticos de Goiás. Novamente, subentende-se que os destinos do Estado estavam preparados operacionalmente para isso. De fato, a pesquisa de Almeida (2002) levanta vários feitos e projetos de diagnóstico para outros municípios não especificados nos planos, a exemplo do levantamento das cavernas em São Domingos, do Programa Integrado de Três Ranchos e do Polo de Desenvolvimento Turístico da Região Leste Goiana. Aqui se percebe um direcionamento para um novo tipo de turismo, voltado para a questão ecológica. Chama também a atenção o destaque dado ao turismo na política nacional para o Centro-Oeste, por meio do Plano de desenvolvimento da Região Centro-Oeste (Brasil, 1986), que apresenta o seguinte diagnóstico:

Apesar de dispor de um rico patrimônio histórico-cultural e paisagístico, o turismo no Centro-Oeste não apresenta aspectos relevantes no quadro econômico da região. Apresentando uma localização central, pouco favorável no contexto nacional, e uma insuficiente rede de infraestrutura, o setor necessita de um conhecimento básico que permita identificar melhor as potencialidades regionais, as formas e os meios mais adequados de se implementar e valorizar tal atividade, colocando-a num plano de importância entre os diversos setores da economia. (Brasil, 1986, p. 60).

A resposta para isso foi o Programa "Dinamização da Exploração e Atração Turística”, além de outros de importante interface com o turismo, 
como o de serviços básicos, a ampliação do papel das pequenas e médias empresas (PME) na região, o de apoio ao desenvolvimento urbano, o de saneamento básico e ambiental e o de ação cultural. Observa-se a alusão feita, nesse documento, às comunidades locais dos destinos. O documento explicita que o aumento dos fluxos turísticos não deve descaracterizar culturalmente a comunidade nativa nem afetar os bens naturais e arqueológicos. Pormenorizando, temas jamais incorporados à política de turismo passaram a ser pauta na agenda governamental (Figura 7).

No plano nacional, ressalta-se o contexto de crise vivido no final dos anos 1980 e a sequência de mudanças quanto à forma de governar repercutidas pela promulgação da Constituição de 1988. No estado de Goiás, o governador Henrique Santillo (1987-1991) lançou a idéia de um novo formato de gestão pública estatal. Já em seu programa de governo (Santillo, 1986), pôs-se em pauta uma nova forma de governar, cujo interesse, segundo consta, assentava-se na "[r]egionalização descentralizada e democratização da Administração Pública com programa de fortalecimento dos municípios", além de defender um crescimento econômico autossustentado, uma política para o meio ambiente, para a cultura e para o desporto e lazer, elementos já referendados, de certo modo, pelo seu antecessor.

Entretanto, na seara do turismo, passa a verificar-se um aviltamento das questões a ele relacionadas, resultando em poucas e discretas medidas no governo Santillo. Entre as medidas propostas estavam: a fundação da União Nacional de Assistência e Turismo dos Servidores Públicos (UNATUR) e da Associação Brasileira de Assistência e Turismo (ABRASTUR). Constam também nos relatórios orçamentários do estado de Goiás de 1990 isolados feitos de promoção e implantação de terminais turísticos, a cargo da Superintendência de Turismo de Goiás. Esse órgão, por sinal, considerando a reestrutura organizacional do Executivo, foi colocado à margem da agenda de prioridades nessa gestão. Uma das maiores provas do descaso quanto à política de turismo foi a extinção do FUNDETUR, criado ainda em 1975.

Para Solha (2004), uma característica da década de 1980, relativa à administração do turismo nos Estados, foi a intensa transformação das estruturas administrativas, o que resvalou na recriação, redução e até extinção de secretarias específicas do turismo fundadas durante a década de 1970. 


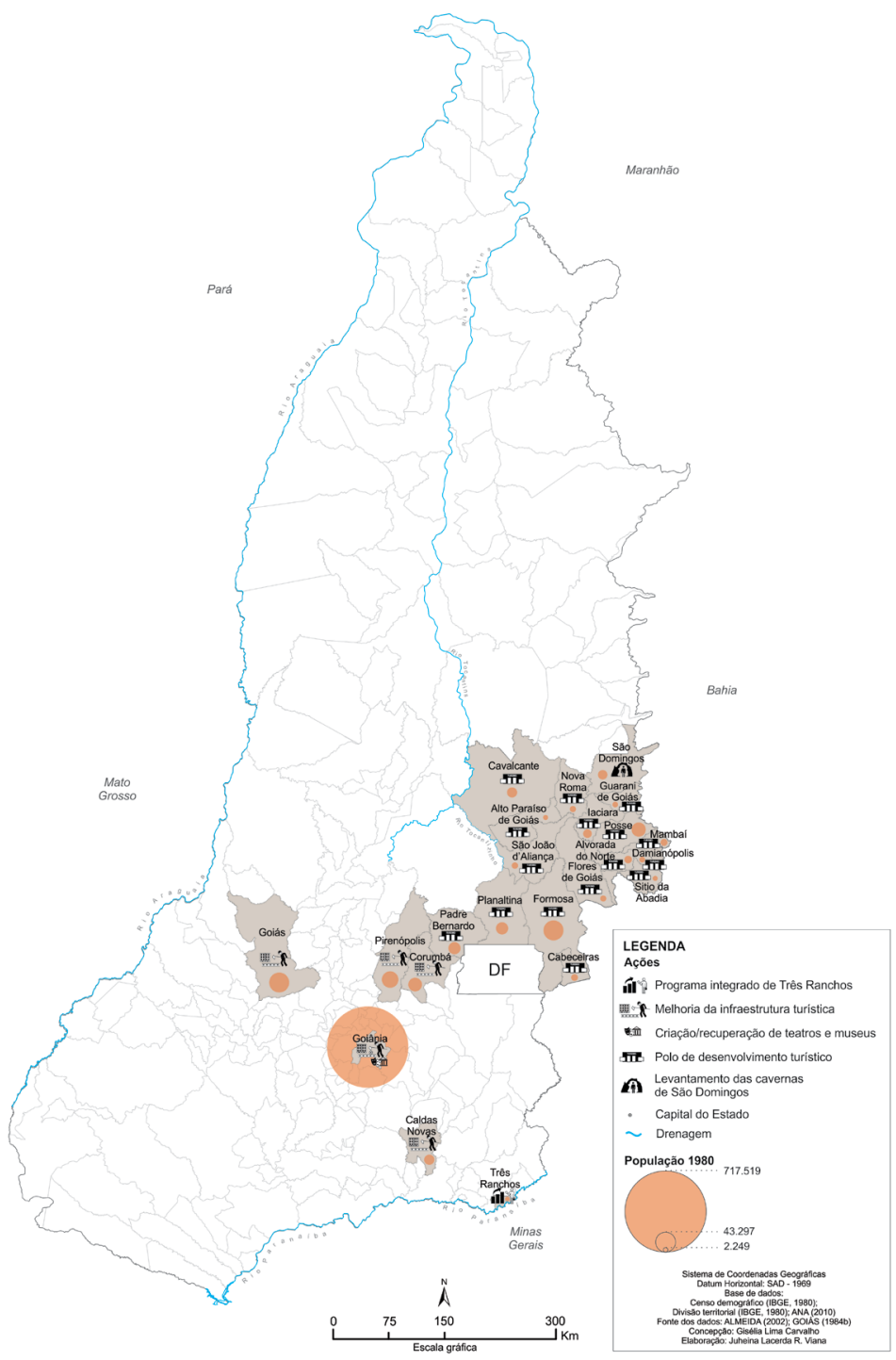

Figura 7 - Mapa da política de turismo no estado de Goiás: ocorrência de ações no governo de Iris Rezende (1983-1986) 
Não fosse a gestão de Iris Rezende, esse período teria sido a síntese do descaso com o desenvolvimento do setor por parte do órgão público estatal. Além da inexistência de uma política clara para o turismo, o período representou um retrocesso e uma descontinuidade das ações estaduais se comparado ao período anterior, como já era previsto em função da crise econômica vivida em toda a década de 1980. O que a atividade turística tirou de proveito nessa fase foi o fato de emergirem no debate político preocupações com temas que estavam em voga no país, surgidas de demandas da sociedade, e que já começavam a afetar o desempenho do setor. Entre estas estavam questões ligadas ao meio ambiente, à cultura e ao significado das comunidades locais, além da necessidade de se pensar um novo formato de gestão que reconsiderasse o papel da escala municipal. Todos esses temas permearão as políticas do setor na nova década.

\section{Considerações finais}

As análises desenvolvidas neste artigo buscaram dilatar a compreensão sobre a política de turismo no território goiano e sobre o processo de formação da sua institucionalização em uma fase que antecede a década de 1990, geralmente associada àquela em que houve melhor planejamento e desempenho do turismo em todo o país.

No período tratado (1961-1990) percebe-se uma evolução não linear com avanços e retrocessos próprios do processo histórico e da conjuntura política. À luz do que ocorria no âmbito nacional e evidenciando maior interesse por parte das instâncias governamentais, no início da década de 1970, foram criados e estruturados os primeiros e principais organismos institucionais pertinentes e tomadas as primeiras medidas para o setor, estratégias fundamentais para a constituição da Política Estadual de Turismo. A crise vivida na década de 1980 refletiu um retrocesso também na política brasileira de turismo, o que reservou para o turismo goiano uma lacuna, a despeito de ações pontuais, sobretudo quanto ao incentivo à construção de hotéis. Por outro lado, cabe destacar que essa década representou avanços na ocorrência de novos temas na sociedade, que, por tamanha convergência com o turismo, resultaram em ganhos para o setor, mormente no bojo das questões ambientais e culturais que asseguraram maior identidade ao produto turístico goiano na atualidade. 
Evidenciou-se que, nessa trajetória, alguns municípios foram sendo alvos rotineiros de ações planejadas e de investimentos, passando a ser, em função disso, um composto da atual oferta turística do Estado, o que assegura que a configuração do turismo que temos hoje é resultado do acúmulo de ações no tempo e do trabalho de diversos atores públicos. Adverte-se sobre a importância de considerar o período anterior à década de 1990, como parte fundamental da constituição da Política Estadual de Turismo, tarefa um tanto esquecida no meio acadêmico.

\section{Notas}

${ }^{1} \mathrm{O}$ site utilizado para a pesquisa foi $<\mathrm{http}$ ///www.casacivil.go.gov.br>, com acesso pelo item "Pesquisa legislação". A investigação foi complementada por meio de pesquisa documental em órgãos oficiais do governo e bibliotecas públicas da cidade de Goiânia.

${ }^{2}$ Lei no 3.040, de 7 de novembro de 1960 (TEIXEIRA, 1961).

${ }^{3}$ Otávio Lage de Siqueira governou o Estado entre janeiro de 1966 e março de 1971.

${ }^{4}$ O estímulo para tanto foi dado pelo Decreto-Lei $n=55 / 66$, que viria a definir a primeira PNT, a criar o CNTur e a Embratur. A partir desse instrumento, fundos foram criados e muitos Estados foram estimulados a estabelecer suas próprias políticas, como ocorreu com Goiás.

${ }^{5}$ Por meio do Decreto 188, de 19 de julho de 1971 (GOIÁS, 1971).

${ }^{6}$ Em nossa pesquisa não foi possível identificar o real papel do GTT, além daquele descrito por Almeida (2002).

${ }^{7}$ Lei n 7.540 , de 12 de setembro de 1972 (GOIÁS, 1972).

${ }^{8}$ Lei no 9.391, de 22 de novembro de 1983 (GOIÁS, 1983a).

${ }^{9}$ A GOIASTUR foi substituída pela Superintendência de Turismo de Goiás, com o objetivo de "executar a política estadual de turismo, na forma em que esta for definida..." (Art. 3ㅇ), conforme o Decreto no 2.303, de 29 de dezembro de 
1983 (GOIÁS, 1983b). O órgão continuou assim até o fim da gestão de Henrique Santillo, em 1991.

${ }^{10}$ Nesse caso, a Superintendência de Turismo de Goiás.

${ }^{11}$ O SENAC foi criado em 1946, pelo Decreto-Lei no 8.621 (BRASIL, 1946), a cargo da Confederação Nacional do Comércio, para organizar e administrar, no território nacional, escolas de aprendizagem comercial.

${ }^{12}$ Essa campanha foi retomada em 2007 pelo Serviço Brasileiro de Apoio às Micro e Pequenas Empresas (Sebrae) em Goiás para intitular o projeto "Cara Brasileira", que visava a projetar imagens de produtos goianos, entre eles o turismo.

\section{Referências}

ALMEIDA, M. G. de. Políticas públicas e o delineamento do espaço turístico goiano. In: (Org.). Abordagens geográficas de Goiás. Goiânia: Ed. UFG, 2002. p. 197-222.

ARRAIS, T. A. Planejamento e desenvolvimento regional: a intervenção governamental e a problemática regional em Goiás. Mercator, Fortaleza, v. 6, n. 12, 2007. Disponível em: <http://www.mercator.ufc.br/index.php/mercator/ article/viewArticle/44>. Acesso em: 06 jan. 2014.

BRASIL. Decreto-Lei $\mathrm{n}^{\circ}$ 55, de 18 de novembro de 1966. Define a política nacional de turismo, cria o Conselho Nacional de Turismo e a Empresa Brasileira de Turismo, e dá outras providências. Legislação, Brasília, DF, 1966a. Portal da Câmara dos Deputados. Disponível em: <http://www2.camara.leg.br/legin/fed/ declei/1960-1969/decreto-lei-55-18-novembro-1966-371224-norma-pe.html>. Acesso em: 08 jun. 2013.

- Decreto-Lei $\mathrm{n}^{\circ}$ 8.621, de 10 de janeiro de 1946. Dispõe sobre a criação do Serviço Nacional de Aprendizagem Comercial e dá outras providências. Legislação, Brasília, DF, 1946. Portal da Câmara dos Deputados. Disponível em: <http://www2.camara.leg.br/legin/fed/declei/1940-1949/decretolei-8621-10-janeiro-1946-416555-norma-pe.html>. Acesso em: 10 jun. 2013.

Secretaria de Planejamento. III Plano Nacional de Desenvolvimento PND. Brasília, DF, 1981.

Ministério do Interior. Superintendência do Desenvolvimento do Centro-Oeste (SUDECO). Plano de desenvolvimento da Região Centro-Oeste. Brasília, DF, 1986.

GOIÁS. Plano de ação do Governo Otávio Lage de Siqueira: triênio 1968-1970. Goiânia, 1968a. 

Goiânia, 1968b.

Mensagem governamental de Otávio Lage de Siqueira à Assembleia. . Linhas de ação de Leonino Di Ramos Caiado (1972-1974). Goiânia, 1971.

. Lei $\mathrm{n}^{\circ} 7.540$, de 12 de setembro de 1972. Define a política estadual de Turismo, o CONTUR e a Empresa de Turismo do Estado de Goiás e dá outras providências. Gabinete Civil da Governadoria, Goiânia, 1972. Disponível em: <http://www.gabinetecivil.goias.gov.br/leis_ordinarias/1972/lei_7540.htm>. Acesso em: 10 nov. 2013.

. Lei $\mathrm{n}^{\mathrm{o}}$ 7.988, de 11 de novembro de 1975. Fixa a Política Estadual de Turismo e as atribuições do Conselho Estadual de Turismo, transforma a Empresa de Turismo do Estado de Goiás - GOIASTUR em sociedade de economia mista, cria o Fundo de Desenvolvimento do Turismo e dá outras providências. Gabinete Civil da Governadoria, Goiânia, 1975. Disponível em: <http://www. gabinetecivil.goias.gov.br/leis_ordinarias/1975/lei_7988.htm>. Acesso em: 15 nov. 2013.

. Diretrizes gerais e setoriais da ação do governo Irapuan Costa Júnior. Goiânia: Oriente, 1976.

. Secretaria do Planejamento e Coordenação. Anuário Estatístico de Goiás - 1978. Goiânia, 1979. v. 1.

Lei $\mathrm{n}^{\circ}$ 9.391, de 22 de novembro de 1983. Autoriza as mudanças que especifica no Sistema Administrativo do Poder Executivo e dá outras providências. Gabinete Civil da Governadoria, Goiânia, 1983a. Disponível em: <http://www.gabinetecivil.goias.gov.br/leis_ordinarias/1983/lei_9391.htm>. Acesso em: 20 nov. 2013.

Decreto $\mathrm{n}^{\circ}$ 2.303, de 29 de dezembro de 1983. Dispõe sobre a instituição da Superintendência de Turismo de Goiás e dá outras providências. Gabinete Civil da Governadoria, Goiânia, 1983b. Disponível em: < http://www.gabinetecivil. goias.gov.br/decretos/numerados/1983/decreto_2303.htm>. Acesso em: 15 nov. 2013.

Plano global de trabalho do governo de Iris Rezende (1983-1987). Goiânia: CERNE, 1984a. Versão 2.

. Plano Setorial de Trabalho: Indústria, Comércio e Turismo -Março 84/ Março 87). Goiânia: CERNE, 1984b. Versão 2.

IBGE. VII Recenseamento Geral 1970: Goiás. Rio de Janeiro, 1971.

SANTILLO, Henrique. Programa de Governo: proposta para debate. Goiânia, 1986.

SOLHA, Karina T. Órgãos públicos estaduais e o desenvolvimento do turismo no Brasil. 2004. 168 f. Tese (Doutorado em Relações Públicas, Propaganda e Turismo) - Escola de Comunicação e Artes, Universidade de São Paulo, São Paulo, 2004.

TEIXEIRA, Mauro B. Plano de Desenvolvimento Econômico de Goiás - 19611965. Goiânia: Secretaria de Governo, 1961. 2 v. 
TEIXEIRA, Priscilla da S. Limites e possibilidades do Programa de Regionalização do Turismo como indutor da cultura da cooperação: região dos negócios em Goiás. 2013. 200 f. Dissertação (Mestrado Profissional em Turismo) - Centro de Excelência em Turismo, Universidade de Brasília, Brasília, DF, 2013.

VALADÃO. Ary. Administração e trabalho. In: Relatório de gestão. Goiânia, 1983.

VELASCO GONZÁLEZ, María. Distintos instrumentos para um mismo fin. Los instrumentos de las políticas públicas como herramienta para el análisis. In: Congreso Español de Ciencia Política y de La Administración, 8., 2007, Valencia. Não publicado.

Gisélia Lima Carvalho - Possui Graduação e Mestrado em Geografia pela Universidade Federal de Goiás. É Doutora em Geografia pela Universidade Federal de Ceará. É professora do Instituto Federal de Educação, Ciência e Tecnologia de Goiás na área de Turismo e Hospitalidade.

Recebido para publicação em 24 de junho de 2015 Aceito para publicação em 19 de agosto de 2015 